\title{
Effects of Egg Size and Different Levels of Humidity during Incubation Period on the Embryonic Development, Hatching Percentage and Chicks Yield of Broiler Breeder
}

\author{
Bassareh $M$ and Rezaeipour $\mathbf{V}^{*}$ \\ Department of Animal Science, Qaemshahr Branch, \\ Islamic Azad University, Iran \\ *Corresponding author: Vahid Rezaeipour, \\ Department of Animal Science, Qaemshahr Branch, \\ Islamic Azad University, Qaemshahr, Iran
}

Received: J anuary 27, 2021; Accepted: February 23, 2021; Published: March 02, 2021

\begin{abstract}
Background: This experiment was performed to investigate the effect of humidity and egg size on the hatchability, embryonic development and chicks yield in ROSS 308 broiler breeder flock.

Methodology: The study was conducted in a completely randomized design with a $3 \times 3$ factorial arrangement. The treatments involved three levels of wet bulb humidity ( ${ }^{\circ} \mathrm{F}$ WB) including $82,82.5$ and $83^{\circ} \mathrm{F}$ and three different egg sizes including small, medium or large. Results: The main effect of humidity level on the total and fertile hatchability (\%) as well as the weight of one-day-old chicks were significant $(P<0.05)$. Treatment with humidity of $82.5^{\circ} \mathrm{F}$ enhanced total and fertile hatchability, while humidity of $83^{\circ} \mathrm{F}$ increased one-day-old chick weight $(P<0.05)$.A better total and fertile hatchability $(\%)$, fertility $(\%)$, chick yield $(\%)$ was observed in medium egg size group $(P<0.05)$. However, the chick weight was greater in large egg size group $(P<0.05)$. The lowest embryonic mortality was belong to medium egg size treatment $(P<0.05)$.
\end{abstract}

Conclusion: According to the results, it was concluded that humidity of $82.5^{\circ} \mathrm{F}$ as well as the medium egg size showed a better impact on the incubation performance.

Keywords: Egg size; Embryonic mortality; Humidity; Incubation

\section{Background}

Factors such as the age of the breeder flock, the ratio of hens to roosters, the presence of weak birds, especially weak male birds in the flock, malnutrition and health status affect the fertility and hatchery performance at the breeder farm level. However, when investigating the optimal environmental conditions of incubation most research has focused on parameters such as temperature, relative humidity, egg turning, and even gases concentrations [1-3]. Among these parameters, proper relative humidity in the incubator is one of the most important environmental factors affecting egg hatchability, embryonic growth and the chick weight at hatch [4]. The water balance of the egg during incubation is a function of the initial water fraction of the contents, the rate of water lost through diffusion across the eggshell and the amount of water produced by metabolism [5]. The desired egg water content has a great effect on the formation of air space at the wide end of the egg (air sac) and subsequent on the embryonic respiration. It has been indicated that sufficient water must be lost to create an adequate air space for efficient inflation of the respiratory air sacs of the hatchling during the period between internal and external pipping [5]. It has been observed that decreased humidity in incubators enhances evaporation and expands the air sacs inside the eggs [6]. Overall, it is well documented that chicks hatch earlier when incubation relative humidity is reduced approximately $10 \%$ [7]. Also, the increase in humidity will cause the air sac to expand late in time and the chick will not be able to breathe at this time.

While relative humidity is critical for proper incubation there is mounting evidence that egg size can have an effect on hatchability and even incubation time [8-11]. Previous studies suggested that egg weight within the intermediate range of 45-56 g would hatch better than small or giant eggs [9]. There are reports that the egg size affects the proportion of internal components of the hatchable eggs. For example, it is reported that small and medium eggs have a greater ratio of yolk component than large eggs [10]. Therefore, it can be hypothesized that changes in egg size due to its nutritional component's such as yolk may affect the embryonic growth and development. However, there are no biological reasons for such assumptions. By monitoring the relationship between incubational relative humidity and egg size (weight) and its subsequent impacts on embryo development, it is possible to obtain more optimal combinations of these two parameters to improve the broiler embryo and chick performance. Therefore, the objective of this study was to investigate the combination effects of different rates of humidity $\left({ }^{\circ} \mathrm{F}\right.$ WB) and egg size on the incubation yield in broiler breeder flocks.

\section{Materials and Methods}

All procedures in this trial were approved by the Department of Animal Science, Islamic Azad University, Qaemshahr Branch. 


\section{Egg selection and experimental treatments}

A total of 2400 hatching eggs were supplied from a commercial broiler breeder farm (ROSS 308) at the northern part of Iran (Amol, Iran). In this experiment, the eggs of a broiler breeder were used at 38 weeks of age. Collected eggs were stored at $18^{\circ} \mathrm{C}$ and $75 \%$ relative humidity for three days. The malformed and defective eggs like misshapen, cracked, dirty, blood-stained and toe-punched were removed and then 1728 eggs were selected from the existing eggs. In order to investigate the effect of egg size on hatching performance, selected eggs were classified according to three different weight groups as small, medium and large. Humidity was set by a wet bulb thermometer, which provides a wet bulb temperature that is utilized to determine the relative humidity at the dry bulb temperature. Therefore, in the present study 3 levels of wet bulb humidity ( $\left.{ }^{\circ} \mathrm{F} \mathrm{WB}\right)$ including $82,82.5$ and $83^{\circ} \mathrm{F}$ was used.

\section{Incubation conditions and chick yield}

One hundred and ninety two (192) eggs of each treatment were set into 4 (replicates) with 48 eggs per each replicate. These replicated trays of each treatment were randomly placed to the top, middle and lower part of the setter of chick master machine (Jamesway, ISI model, 95, 040 eggs). The setters were operated at a temperature of $37.5^{\circ} \mathrm{C}$ and the humidity inside the setters was adjusted based on experimental treatments in ranges of $82,82.5$ and $83^{\circ} \mathrm{F}$. All eggs were turned after every hour. On the $19^{\text {th }}$ day of the incubation period, all experimental eggs were transferred into hatchers by separate baskets. Finally, on the 21st of the incubation period, the hatched chicks were transferred to the chicken's room by separate baskets and the average chick weight of each replicates was measured. In this study, the chick yield was also calculated by [9] method. Chick yield is the average chick weight divided by the average egg weight at the time of setting into incubator multiplied by 100 .

\section{Embryonic mortality, fertility and hatchability}

All experimental eggs of each replicates were weighed prior to setting into incubator to record average weight. To measure the egg weight loss percentage, the average weight of eggs in each replicates was recorded at 10,15 and 21 day of incubation.Also, in order to assess embryonic mortality, all experimental eggs were candled on days 10,15 , and 21 of the incubation period, and embryonic mortality related to each period and the whole of incubation period ( 1 to 21 ) were recorded.

Table 1: Effects of humidity levels and egg size on the egg weight loss, total and fertile hatchability.

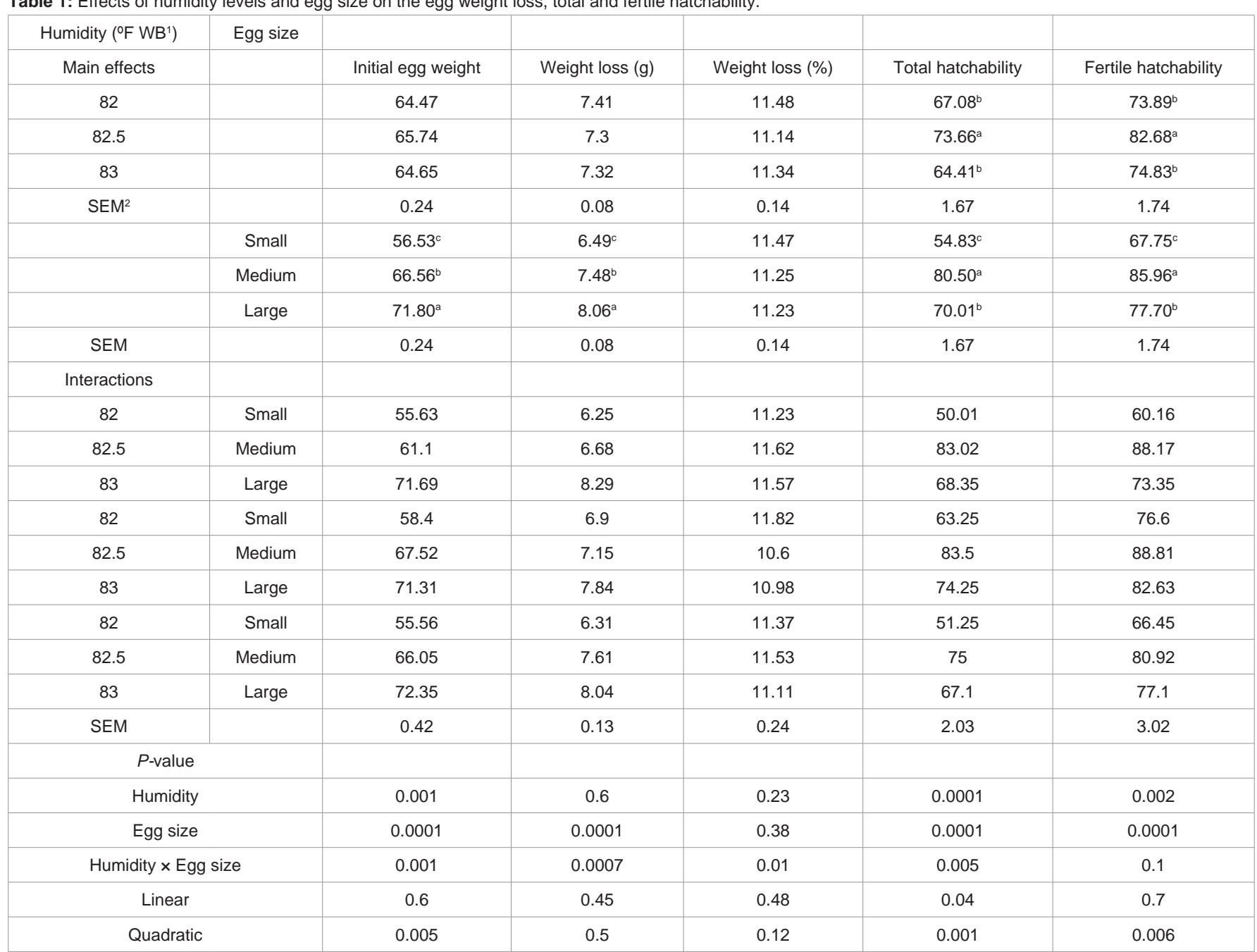


In this study, the percentage of fertility per replicate was determined on the 18th day of incubation period. The fertility rate was calculated based on the number of fertile eggs divided by the total number of egg incubated multiplied by 100 . The total hatchability percentage was calculated in each replicate by dividing the number of hatched eggs by the total number of eggs set in each replicate multiplied by 100 . Also, the hatch of fertile egg was determined as in each replicate as follow: total hatchability divided by fertility rate multiplied 100.

\section{Statistical analysis}

This experiment was performed in a completely randomized design with a $3 * 3$ factorial arrangement, including 3 egg sizes and 3 humidity levels. The statistical model of the design was as follow:

$$
\mathrm{Y}_{\mathrm{ijk}}=\mu+\mathrm{A}_{\mathrm{i}}+\mathrm{B}_{\mathrm{j}}+\mathrm{AB}_{\mathrm{ij}}+\mathrm{e}_{\mathrm{ijk}}
$$

All data obtained in this experiment were statistically analyzed by SAS software (2001). Where significant effects were detected, means were separated by tukeys test. Threshold for significance was $\mathrm{P}<0.05$.

\section{Results}

The effects of egg size and humidity levels on the egg weight loss, total and fertile hatchability are shown in (Table 1). The main effect of humidity on the total and fertile hatchability was significant $(\mathrm{P}<0.05)$ and treatment with humidity of $82.5^{\circ} \mathrm{F}$ had the greatest hatchability compared to other humidity values. The results in (Table 1) also indicated that the egg weight loss was higher in large size eggs $(\mathrm{P}<0.05)$. However, the greatest values for total and fertile hatchability were observed in medium egg size treatment $(\mathrm{P}<0.05)$.

According to the results in (Table 2), the chick weight (gr) was greater in treatment with humidity of $83^{\circ} \mathrm{F}(\mathrm{P}<0.05)$. In this regard, large egg size resulted in greater chick weight (gr) when compared to other egg sizes $(\mathrm{P}<0.05)$. The results in (Table 2$)$ indicated that the higher and lower fertility percentage belongs to the medium and small egg sizes, respectively $(\mathrm{P}<0.05)$.

The results of the effects of experimental treatments on the embryonic mortality are presented in (Table 3). According to the results, the lowest embryonic mortality was observed in medium egg size on 1-10 and 1-21 days of incubation $(\mathrm{P}<0.05)$, While the small egg size treatment had the highest embryonic mortality at the same time $(\mathrm{P}<0.05)$.

Table 2: Effects of humidity levels and egg size on the chick weight, fertility and chick yield.

\begin{tabular}{|c|c|c|c|c|c|}
\hline Humidity $\left({ }^{\circ} \mathrm{F} \mathrm{WB}^{1}\right)$ & Egg size & & & & \\
\hline Main effects & & Chick weight (g) & Infertility (\%) & Fertility (\%) & Chick yield (\%) \\
\hline 82 & & $41.55^{b}$ & 9.65 & 90.35 & 64.67 \\
\hline 82.5 & & $42.64^{\mathrm{a}}$ & 10.96 & 89.04 & 64.95 \\
\hline 83 & & $42.92^{\mathrm{a}}$ & 14.03 & 85.96 & 66.46 \\
\hline SEM $^{2}$ & & 0.29 & 1.39 & 1.4 & 1.87 \\
\hline & Small & $37.89^{c}$ & $18.64^{\mathrm{a}}$ & $81.36^{b}$ & $67.07^{a}$ \\
\hline & Medium & $43.16^{\mathrm{b}}$ & $6.35^{b}$ & $93.64^{\mathrm{a}}$ & $64.86^{\mathrm{b}}$ \\
\hline & Large & $46.05^{a}$ & $9.64^{b}$ & $90.35^{a}$ & $64.14^{b}$ \\
\hline SEM & & 0.29 & 1.39 & 1.4 & 1.87 \\
\hline Interactions & & & & & \\
\hline 82 & Small & 37.49 & 16.44 & 83.55 & 67.39 \\
\hline 83 & Large & 44.57 & 6.57 & 93.42 & 62.17 \\
\hline 82 & Small & 38.68 & 17.1 & 82.89 & 66.29 \\
\hline 82.5 & Medium & 43.45 & 5.91 & 94.08 & 64.35 \\
\hline 83 & Large & 45.78 & 9.86 & 90.13 & 64.21 \\
\hline 82 & Small & 37.52 & 22.37 & 77.63 & 67.54 \\
\hline 82.5 & Medium & 43.44 & 7.23 & 92.76 & 65.78 \\
\hline 83 & Large & 47.79 & 12.5 & 87.5 & 66.06 \\
\hline SEM & & 0.51 & 2.42 & 2.41 & 0.93 \\
\hline \multicolumn{6}{|c|}{$P$-value } \\
\hline \multicolumn{2}{|c|}{ Humidity } & 0.007 & 0.09 & 0.1 & 0.07 \\
\hline \multicolumn{2}{|c|}{ Egg size } & 0.0001 & 0.0001 & 0.0001 & 0.001 \\
\hline \multicolumn{2}{|c|}{ Quadratic } & 0.27 & 0.62 & 0.61 & 0.35 \\
\hline
\end{tabular}


Table 3: Effects of humidity levels and egg size on the embryonic mortality during incubation.

\begin{tabular}{|c|c|c|c|c|c|}
\hline Humidity $\left({ }^{\circ} \mathrm{F}\right.$ WB $\left.{ }^{1}\right)$ & Egg size & \multicolumn{4}{|c|}{ Embryonic mortality (\%) } \\
\hline Main effects & & $0-10$ & $8-15$ & $15-21$ & total \\
\hline 82 & & 6.14 & 2.41 & 5.04 & 13.59 \\
\hline 82.5 & & 5.48 & 1.53 & 4.38 & 11.4 \\
\hline 83 & & 5.47 & 3.06 & 5.92 & 14.47 \\
\hline \multirow[t]{4}{*}{$\mathrm{SEM}^{2}$} & & 0.6 & 0.51 & 0.76 & 1.57 \\
\hline & Small & $8.99^{a}$ & 3.28 & 5.48 & $17.76^{a}$ \\
\hline & Medium & $3.94^{\mathrm{b}}$ & 1.97 & 4.27 & $10.31^{b}$ \\
\hline & Large & $4.16^{\mathrm{b}}$ & 1.75 & 5.46 & $11.40^{\mathrm{b}}$ \\
\hline SEM & & 0.6 & 0.51 & 0.76 & 1.57 \\
\hline \multicolumn{6}{|l|}{ Interactions } \\
\hline 82 & Small & 10.52 & 3.94 & 7.89 & 22.37 \\
\hline 82.5 & Medium & 1.31 & 1.97 & 2.63 & 5.92 \\
\hline 83 & Large & 6.57 & 1.31 & 4.6 & 12.49 \\
\hline 82 & Small & 5.91 & 2.64 & 1.17 & 10.52 \\
\hline 82.5 & Medium & 7.23 & 0.65 & 4.6 & 12.5 \\
\hline 83 & Large & 3.28 & 1.31 & 6.57 & 11.8 \\
\hline 82 & Small & 10.52 & 3.28 & 6.56 & 20.39 \\
\hline 82.5 & Medium & 3.28 & 3.26 & 5.91 & 12.51 \\
\hline 83 & Large & 2.63 & 2.63 & 5.26 & 10.52 \\
\hline SEM & & 1.49 & 0.87 & 1.31 & 2.72 \\
\hline \multicolumn{6}{|c|}{$P$-value } \\
\hline \multicolumn{2}{|c|}{ Humidity } & 0.82 & 0.11 & 0.37 & 0.35 \\
\hline \multicolumn{2}{|c|}{ Egg size } & 0.0003 & 0.08 & 0.5 & 0.004 \\
\hline \multicolumn{2}{|c|}{ Humidity $\times$ Egg size } & 0.006 & 0.64 & 0.02 & 0.03 \\
\hline \multicolumn{2}{|c|}{ Linear } & 0.59 & 0.36 & 0.42 & 0.69 \\
\hline \multicolumn{2}{|c|}{ Quadratic } & 0.75 & 0.08 & 0.24 & 0.18 \\
\hline
\end{tabular}

${ }^{1}$ WB: Wet Bulb

${ }^{2}$ SEM: Standard Error of the Mean

\section{Discussion}

According to the present study, a moderate humidity $\left(82.5^{\circ} \mathrm{F}\right)$ will positively affect the total and fertile hatchability, and chick weight during incubation time. In parallel with this result, it is reported that chick body weight at hatch enhanced with increasing relative humidity [12]. However and in contrast with the present results, It is observed that the absolute weights of one day old chicks hatched from eggs incubated at $70 \% \mathrm{RH}$ were not significantly different from those incubated at $40 \% \mathrm{RH}$ [13]. The maintenance of proper environmental control such as humidity within the hatchery have always been critical to good hatchability and chick quality [1]. It is well documented that the change in incubation humidity had a significant impact on the number of chicks, which hatched [6]. On the other hand, relative humidity content in incubation can have a large influence on embryonic dehydration during the hatchery period, as well as the length of time from hatching to removal from the hatcher [12]. The manipulation of relative humidity during incubation is one of the practical strategies to improve embryonic development, hatchability and chick quality by the modifying gases and water exchange through the eggshell [14]. Total and fertile Hatchability and chick weight are qualities that may be controlled by incubation egg water loss. The moisture loss is critical and affected most when embryonic metabolism reaches a plateau and egg water loss is also inversely related to incubation relative humidity [7]. On the other hand, it has been reported that egg weight loss may be due to the evaporation of water in the egg, and monitoring the ambient humidity around the egg during incubation can reduce the rate of egg weight loss [5].

Undoubtedly, embryonic mortality, fertility and hatchability are key factors that have a major impact on the economic efficiency of hatchery. Therefore, interpreting the results of egg size on the fertility and hatchability traits and subsequent chick quality may be one of the most important challenges in the hatchery industry. In the present experiment, egg size had a severe effect on the egg weight loss, fertility, hatchability and embryonic mortality. There are some reports, which is in parallel with these findings [15-17]. It has been documented that there was a significant relationship between egg size and total hatchability of broiler breeders and also showed that the highest fertility and hatchability percentage were in the group of small, medium and large eggs, respectively [9]. Also, the positive correlation between hatchability and egg size has been studied [16] However, the non-significant influence of egg size on the total and fertile hatchability has been found in COBB 500 broiler breeder [18]. In a study with Venda chickens, it is observed that there is an inverse relationship between egg weight and hatchability percentage [17]. The results achieved on hatchability and fertility in response to egg size in the present study conform with earlier studies which suggested the setting of medium egg size in order to obtain good hatchability $[16,19]$. In the present study, smaller eggs were associated with higher embryonic mortality, and the results of this study are consistent with the findings of other studies [9]. One of the reasons for this finding is that small eggs may have less nutrients and eggshell pores that may affect embryonic metabolism such as lipid utilization and respiration and subsequent embryonic growth during incubation period [20].

\section{Conclusions}

In the view of the results of this study, it is concluded that most of the incubation parameters are related to the egg size. In this study, medium-sized eggs showed the best performance such as fertility and hatchability during the incubation period. Also, based on the results of this study, it can be suggested that the humidity content of $82.5 \%$ ${ }^{\circ} \mathrm{F}$ compared to other humidity ranges improves total and fertile hatchability.

\section{References}

1. Mauldin JM, MacKinnon IR. Hatchery Ventilation and Environmental Control. Avian Biology Research. 2009; 2: 87-91.

2. Archer GS. Effect of two different commercially available white light LED fixtures on broiler hatchability and chick quality. British Poultry Science. 2018; 59: $251-255$

3. Khan MJA, Khan SH, Bukhsh A, Abbas MI, Javed M. Effect of Different Storage Period on Egg Weight, Internal Egg Quality and Hatchability Characteristics of Fayumi Eggs. Italian Journal of Animal Science. 2013; 12: 51.

4. Peebles E, Brake J, Gildersleeve R. Effects of eggshell cuticle removal and incubation humidity on embryonic development and hatchability of broilers. Poultry Science. 1987; 66: 834-840. 
5. Ar A, Deeming DC. Roles of Water and Gas Exchange in Determining Hatchability Success. Avian Biology Research. 2009; 2: 61-66.

6. Peebles E, Burnham MR, Garden CW, Brake J, Bruzual JJ, Gerard PD Effects of incubational humidity and hen age on embryo composition in broiler hatching eggs from young breeders. Poultry Science. 2001; 80: 1299-1304.

7. Swann GS, Brake J. Effect of Incubation Dry-Bulb and Wet-Bulb Temperatures on Time of Hatch and Chick Weight at Hatch1. Poultry Science. 1990; 69: 887-897

8. Archer GS, Mench JA. The effects of the duration and onset of light stimulation during incubation on the behavior, plasma melatonin levels, and productivity of broiler chickens. Journal of Animal Science. 2014; 92: 1753-1758.

9. Iqbal J, Khan SH, Mukhtar N, Ahmed T, Pasha RA. Effects of egg size (weight) and age on hatching performance and chick quality of broiler breeder. Journal of Applied Animal Research. 2016; 44: 54-64.

10. Ulmer-Franco A, Fasenko G, O'Dea E. Christopher, Hatching egg characteristics, chick quality, and broiler performance at 2 breeder flock ages and from 3 egg weights. Poultry Science. 2010; 89: 2735-2742.

11. Caglayan T, Garip M, Kirikci K, Gunlu A. Effect of egg weight on chick weight, egg weight loss and hatchability in rock partridges (A. graeca). Italian Journa of Animal Science. 2009; 8: 567-574.

12. Bruzual J, Peak SD, Brake J, Peebles ED. Effects of relative humidity during incubation on hatchability and body weight of broiler chicks from young breeder flocks. Poultry Science. 2000; 79: 827-830.
13. Robertson I. Studies on the effect of humidity on the hatchability of hens eggs II. A comparison of hatchability, weight loss and embryonic growth in eggs incubated at 40 and $70 \% \mathrm{RH}$. The Journal of Agricultural Science. 1961 57: 195-198.

14. El-Hanoun A, Rizk RE, Shahein EHA, Hassan NS, Brake J. Effect of incubation humidity and flock age on hatchability traits and posthatch growth in Pekin ducks. Poultry Science. 2012; 91: 2390-2397.

15. Gheisari AA. The Effects of Weight and Storage Period on Albumen $\mathrm{pH}$ and Hatchability of Hatching Eggs. JSTNAR. 1999; 2: 77-88.

16. Abiola S. Effect of egg size on hatchability of broiler chicks. Archivos de Zootecnia. 2008; 57: 83-86.

17. Ng'ambi J, Thamaga MW, Norris D, Mabelebele M, Alabi OJ. Effects of egg weight on hatchability, chick hatch-weight and subsequent productivity of indigenous Venda chickens in Polokwane, South Africa. South African Journal of Animal Science. 2013; 43: S69-S74.

18. Ramaphala N, Mbajiorgu CA. Effect of egg weight on hatchability and chick hatch-weight of COBB 500 broiler chickens. Asian Journal of Animal and Veterinary Advances. 2013; 8: 885-892.

19. Asuquo B, Okon B. Effects of age in lay and egg size on fertility and hatchability of chicken eggs. East African Agricultural and Forestry Journal. 1993; 59: 79-83.

20. McNoughton L, Gous R. The effect of egg size on pre and post natal growth of broiler breeder. World's Poultry Science Journal. 1999; 15: 34-38. 